\title{
Fenomenologia do design contemporâneo
}

*

Dijon de Moraes é professor titular da Universidade do Estado de Minas Gerais - UEMG. PhD em Design pelo Politecnico di Milano, com pós-doutoramento no mesmo instituto. Pelo conjunto de sua obra prática e teórica obteve reconhecimento no Brasil e exterior. É autor dos premiados livros: Limites do Design; Análise do design brasileiro e Metaprojeto: o design do design. Ocupou por duas vezes o cargo de reitor da UEMG; Fundador do Centro de Estudos Teoria, Cultura e Pesquisa em Design e Editor dos Cadernos de Estudos Avançados em Design da ED-UEMG. Atualmente é Visiting Professor junto ao Politécnico di Milano e na Università Degli Studi di Campania em Nápoles; Membro do colégio de doutores em design da Università di Bologna.

<dijon.moraes@uemg.br>
Resumo Este artigo propõe uma reflexão sobre o tema "Fenomenologia do Design Contemporâneo". o mesmo apresenta os desafios para o design em campo aberto, fuzzy e difuso, onde se demonstra que as constantes mudanças de cenário e a fluidez das fronteiras entre arte e design fez surgir um terreno tênue, frágil e incerto para o ensino de design no século XXI..

Palavras chave Teoria do design, Fenomenologia do design contemporâneo, Design em campo aberto, Design em campo fuzzy e difuso. 


\section{Fhenomenology of contemporay design}

Abstract This paper offers a reflection on the theme of "Contemporary Design Phenomenology". It presents the challenges for the design in the open field, fuzzy and diffuse, where he demonstrates that the constant changes in scenarios and the fluidity of boundaries between art and design have created a fragile and uncertain terrain for design teaching in the 21st century.

Keywords Theory of design, Contemporary Design Phenomenology, Design in the open field, Design in the fuzzy and diffuse field.

\section{Fenomenología del diseño contemporáneo}

Resumen Este artículo propone una reflexión sobre el tema "Fenomenología del diseño contemporáneo". Presenta los desafíos para el diseño en el campo abierto, fuzzy y difuso, donde se demuestra que los cambios constantes del escenario y la fluidez de los límites entre el arte y el diseño dieron lugar a un terreno tenue, frágil e incierto para la enseñanza del diseño en el siglo XXI.

Palabras clave Teoria del diseño, Fenomenología del diseño contemporáneo, Diseño en el campo abierto, Diseño en el campo fuzzy y difuso. 


\section{Mudanças de cenário na arte e no design}

Períodos distintos e diversas referências históricas, ocorridas ao longo dos tempos, podem ser tomados como exemplos para destacarmos as rupturas ocorridas nas artes e no design. Nas artes, como sabemos, devido à sua tradição milenar, esse fenômeno sempre ocorreu primeiro e com mais frequência que na atividade de design.

O design, se tomarmos como referência o processo de produção industrial no formato seriado, se inicia como atividade profissional somente a partir do século VIII. Não obstante isso, sabemos todos que o design já existia, há muitos séculos, como instrumento de concepção dos artefatos, objetos e utensílios de uso cotidiano dentro da nossa cultura material e civilizatória.

É curioso notar, que somente no século XX, dentro do período denominado de "Moderno", que a arte e o design (através de seus protagonistas e mestres pioneiros) começam a se dialogar com mais frequência e se aproximam entre si, na condição de interface e fronteira, mas também de confronto e ruptura.

Dentro dos diversos e abrangentes movimentos artísticos que prenunciaram a arte moderna no século XX, vários deles promoveram encontros entre a arte e o design. Um exemplo, neste sentido, veio através da inserção de objetos anônimos, escolhidos pelos próprios artistas, para serem convertidos em obras de arte ou comporem como parte das mesmas. Estas intervenções, conhecidas como ready-made, acabaram por auxiliar na desconstrução da "sacralização da arte" e se aproximaram da cultura material produzida através dos preceitos do design.

Foram especificamente alguns movimentos como dadaísmo, futurismo, surrealismo e cubismo, que compuseram a vanguarda artística europeia nas duas primeiras décadas do século XX, e que melhor promoveram as mudanças estéticas e interpretativas nas artes. Esta realidade, de certa forma, contribuiu também para a aproximação do diálogo entre arte e design.

Dentre as várias obras realizadas neste período de ruptura nas artes, e que contemplaram o uso de objetos de uso cotidiano como parte das suas narrativas, mensagens e por fim estéticas, coloco luz sobre algumas delas que, a meu ver, melhor espelham e representam essa reflexão.

Tomando, primeiramente, como referência, a obra "Roda de Bicicleta" de Marcel Duchamp (1887-1968), observamos, por vez, se tratar de uma simples roda de bicicleta afixada sobre um banco de madeira. Vejamos que como peça de arte, a mesma nos passa uma sensação de completa inutilidade, sendo por si uma provocação inerente à arte. Por outro lado, como peça de design, que tem entre as suas condicionantes a funcionalidade, a mesma somente teria valor se desmembrássemos as duas peças que a compõe, ou seja: a roda e o banco que separadamente e nos seus contextos reais de uso, teriam utilidades práticas e funcionais condizentes. Uma delas como parte de um produto de locomoção (a bicicleta) e, a outra como um produto para se assentar (o banco). Estes dois objetos, de concepção in- 
dustrial, uma vez inseridos em um contexto fora do inicialmente pensados, tornam-se uma instigante obra de arte, desafiando assim, em 1913, as ideias tradicionalmente pré-concebidas sobre a definição de arte e de design.

Essa intrigante combinação feita por Duchamp, ao tirar os objetos de seu cenário habitual, para os quais foram concebidos, para colocá-los em um novo contexto até então incomum, é ao mesmo tempo uma rejeição à um objeto de design feito em escala industrial e, de igual forma, também uma rejeição à arte como até então conhecida. Tornando assim por inaugurar o conceito de ready-made que se tornou prática junto aos artistas dadaístas à época.

De igual forma, temos em outra obra de Duchamp os mesmos conceitos aplicados na "Roda de Bicicleta". Trata-se da obra "Fonte", também conhecida como "Urinol ou Mictório", que foi realizada pelo artista em 1917. A Fonte é basicamente um mictório produzido industrialmente em porcelana branca e, que foi concebido na sua origem como um produto para banheiros masculinos. A propósito, devemos reconhecer se tratar de uma excelente solução de design para banheiros públicos masculinos, vez que o mesmo possibilita um rápido uso em alternativa ao vaso sanitário que exige a construção de uma cabine ao seu entorno.

O mictório, por vez, fora do seu contexto de uso como um utensílio de banheiros masculinos, passa a ter uma interação completamente diferente do originalmente pensado. Desta forma, quando exposta em uma galeria de arte ou museu, o mictório ganha a dimensão de uma obra de arte. Esta obra, inclusive foi alvo de vandalismo por parte de um visitante quando estava exposta no Centro George Pompidou em Paris, que a atacando com um martelo dizia ser também uma performance artística (desta vez por parte do observador) que quis se interagir e participar da obra de arte.

O mictório convertido em obra de arte em museu deixa, portanto, a sua função primeira como uma solução de design, distanciando assim do conceito de sua concepção inicial. Dificilmente um usuário do mictório, em um banheiro, estaria estimulado a destruí-lo com um martelo, pois ali o mesmo cumpre outra função diferente da arte que estimula e provoca. No banheiro, o mictório comunica de forma natural e direta ao usuário a sua função de uso e de affordance. ${ }^{1}$

No ano de 2019, a obra de René Magritte (1898-1967) “Ceci n'est pás une pipe", fez 90 anos da sua primeira apresentação pública. Fato esse que gerou uma série de comemorações em diversos países por meio de concursos para releituras e reinterpretações da própria obra através de manifestos, cartazes e deplians desta marcante obra que foi exposta pela primeira vez em 1929.

Interessante notar, dois fatos bastante curiosos nesta obra que é reconhecida como sendo pré-modernista: a primeira trata-se da negação à arte como até então conhecida, trazendo para o interlocutor, ou seja, para o observador visitante, a função de interpretação e participação na mesma que, agora não mais pertencia somente ao artista. Magritte ao afirmar, mostrando um cachimbo, que aquilo não era um cachimbo, ele "trai a própria imagem" por ele mesmo apresentada e, passa a dividir a concepção da sua obra com diferentes interlocutores. Esses interlocutores são observa- 
dores com percepções e interpretações distintas, inclusive que possam até mesmos ser contrários à sua afirmação. Outro fato curioso nesta obra de Magritte, também como ocorrido anteriormente em demais obras de Duchamp, foi à inserção de um artefato em sua obra de arte, pois ao inserir um produto produzido em escala industrial, ou seja: um produto de design em sua obra, Magritte insere, de igual forma, um objeto de concepção técnico-artístico-funcional no universo livre das artes.

Ainda nessa mesma linha de raciocínio, temos em Andy Warhol (1928-1987) outro oportuno exemplo de inserção de objetos de uso cotidiano nas artes. Desta vez trata-se de objetos comerciais e populares direcionados à grande massa de consumidores como: as embalagens de sabão em pó ou sopas semiprontas. De fato, em 1962, como expoente da Pop Art Andy, Warhol retira dos supermercados as embalagens da Sopa de Tomate Campbell's e a Caixa de Sabão em Pó Brillo e às elevam à condição de arte. Assim nos relata Stephen Farthing (1950): "Nos Estados Unidos, o ano de 1962 foi crucial, com as primeiras exposições de futuros expoentes da Pop Art como Roy Liechtenstein (1923-1997), Tom Wesselman (1931-2004) e Andy Warhol (1928-1987). Num primeiro momento, os cartuns de Liechtenstein, como Whaam! e, as reproduções em silkscreen de Warhol, como a Lata de Sopa Campbell foram recebidas com muita incompreensão" (FARTHING, 2011, p. 485).

Deve ser observado, que esta "contaminação positiva" entre arte e design também ocorre de forma inversa, isto é: do design para a arte. Neste sentido, temos no designer italiano Achille Castiglioni (1918-2002) entre seus protagonistas precursores. Obcecado pelos objetos anônimos, Castiglioni dedica seu interesse pelo universo de produtos de uso cotidiano que não carregam assinaturas nem a marca de designers profissionais. Ele cita as variedades de tesouras, martelos, guarda chuvas, cadeiras dobráveis e uma vasta gama de produtos e objetos comuns que cumprem importante função de uso e social, mas cujo projeto e concepção não se pode precisar a autoria.

Encontramos no estudioso Sergio Polano (1950) a análise mais minuciosa e cuidadosa sobre a obra e o método de trabalho de Castiglioni, que assim a descreve:

\footnotetext{
Aquele típico itinerário projetual que toma como referência os componentes artesanais e industriais, já presentes na cultura material dos objetos, para remontá-los em novas possíveis combinações, para direcioná-las à produção em série: uma espécie de montagem dadaísta, da poética do ready-made a qual não é estranha à intenção irônica e a desmistificação das valências excessivamente solenes e de certo modo 'hostil' que muitas vezes acompanham a atividade dos designers (POLANO, 2001, p. 122).
}

Dentre os vários produtos concebidos por Castiglioni nessa linha, temos no banco Mezzadro criado pelo designer para a mostra da XI Triennale d'Archittetura e Design di Milano, em 1957, que bem representa o discurso 
narrativo de Polano vez que Castiglioni faz uso de um assento de trator acrescidos de apenas três outros componentes (esses também destinadas a outros usos e funções anteriores), para conceber um banco que somente em 1971, começa a ser de fato comercializado pela empresa italiana Zanotta.

$\mathrm{Na}$ mesma linha de tempo e época do banco Mezzadro, Castiglioni desenvolve também, em 1957, o banco Sella onde tomando como inspiração e referência o mocho de ordenha constituído de um único pé de apoio que vai do assento ao pavimento. Para este trabalho Castiglioni transporta desta vez, um selim de bicicleta para um tubo metálico que se apoia em uma base em semicírculo confeccionada em ferro fundido. Para Sergio Polano, neste trabalho Castiglioni também apresenta:

A irônica e surreal exasperação da idéia de object trouvé, realizado com elementos industriais para o banco de telefone que se traduz em assento 'semi-em-pé' tendo como base o equilíbrio dinâmico, uma forma pensada para aqueles objetos ‘que estão sempre em pé' (POLANO, 2001, p. 123).

\section{Mudanças interpretativas e conceituais na arte e no design}

O semiólogo Umberto Eco (1932-2016), que desde os anos cinquenta vinha se dedicando aos estudos sobre a teoria da informação e da semiótica, em seu conhecido ensaio "Obra Aberta", de 1962, discorre que toda obra de arte pode ser aberta porque a mesma comporta várias interpretações e, onde por vez o interprete participa ativamente da construção final do objeto ou da ação artística.

De acordo ainda com Eco, na medida em que o observador/intérprete é convidado a participar da descoberta e decodificação da obra, vem criado um dualismo entre a obra fechada e a obra aberta. O conceito de obra aberta é também uma tentativa de aproximação do autor, em busca de um entendimento da arte contemporânea nas suas mais abrangentes e variantes vertentes conceituais. Para Eco, a obra fechada, por si só, não é mais capaz de lidar sozinha com a pluralidade e a multiplicidade do mundo. Por isso mesmo, o conceito de obra aberta traz a possibilidade da promoção do intérprete à agente participativo e interpretativo da arte, hoje cada vez mais descentralizada e plural.

Faz-se por oportuno registrar, que a tradução no Brasil do livro "Obra Aberta" do Umberto Eco, foi feita na década de sessenta por Giovanni Cutolo (1939), quando este ainda vivia e trabalhava no Brasil. Uma outra importante referência quanto à pesquisa sobre as mudanças interpretativas, filosóficas e conceituais ocorridas na arte, arquitetura, urbanismo e design no século XX, se faz presente, de forma também bastante didática, nas pesquisas e estudos de Giulio Carlo Argan (1909-1992). Para este estudioso, 
a arte, por si só como matéria física, perde cada vez mais a sua importância como resultado exclusivo do artista e, na mesma linha de pensamento de Umberto Eco aponta para uma possível abertura para a participação do observador. Neste sentido, assim discorre Argan:

\footnotetext{
No âmbito das poéticas existenciais ou do informal, o problema é colocado em termos totalmente diversos: a matéria tem, sem dúvida, extensão e duração, mas ainda não tem, ou já deixou de ter uma estrutura espacial e temporal. Sua disponibilidade é ilimitada; manipulando-a, o artista estabelece com ela uma relação de continuidade essencial, de identificação. É verdade que não tem, nem pode adquirir um significado definido, isto é, tornar-se objeto; todavia, justamente por ser e permanecer problemática, o artista nela identifica sua própria problematicidade, a incerteza quanto ao próprio ser, a condição de estranhamento em que é posto pela sociedade (ARGAN, 1995, p. 542).
}

Podemos perceber, que tanto Eco quanto Argan falam a mesma linguagem quando eles se referem à questão do signo na arte. Enquanto Eco, através da teoria da informação, busca entender a relação do observador com a obra observada, Argan por vez se atém à busca pelo significado e assim discorre:

\footnotetext{
A noção de signo emerge, na arte europeia, no exato momento em que se esboçam as pesquisas semiológicas e estruturalistas em outras disciplinas, especialmente na glotologia; ou seja, quando cada disciplina, para desenvolver sua metodologia, sente a necessidade de analisar e elucidar o significado dos signos. Na arte, a pesquisa significa também o início da exigência de 'requestionar' a razão e a função institucional da própria arte (Idem, pág. 551).
}

Interessante notar, que para o italiano Attílio Marcolli (1930-2010), estudioso e teórico da percepção visual e das cores, autor entre outros do livro "Teoria do Campo", não foi por acaso que Argan concluiu a sua pesquisa sobre a Arte Moderna justamente com dois expoentes da Pop Art americana que vem ser: Roy Liechtenstein e Andy Warhol. Segundo Marcolli, trata-se justamente de uma mensagem do Argan sobre o fim da arte, pelo menos nos moldes até então conhecidos. De fato, assim descreve Argan, sobre a obra de Liechtenstein, no seu reconhecido ensaio "Arte Moderna", no capítulo intitulado: "Do iluminismo aos movimentos contemporâneos": 


\begin{abstract}
“A operação de Liechtenstein é exata como uma análise de laboratório. O objeto de análise é a estrutura da imagem nas histórias em quadrinhos (comic strips), um dos meios de comunicação de massa mais consumidos. Essas imagens, divulgadas em milhões de exemplares pela imprensa diária e periódica, não pretendem ser obras de arte: comunicam sintética e visualmente um conteúdo narrativo. Sua estrutura deve atender a duas exigências: serem reprodutíveis com os processos tipográficos normais, e provocar nos leitores (se assim podem ser chamados) um certo impacto emotivo." (Ibidem, p. 646).
\end{abstract}

E quanto a Andy Warhol, Argan segue uma análise crítica bem próxima da tecida para a obra de Liechtenstein, e no mesmo ensaio ele analisa ainda a obra de Warhol desta forma:

\footnotetext{
Tal como Liechtenstein, Warhol retira a imagem dos circuitos de informação de massa, mas apresenta-a gasta, desfeita, consumida. É uma imagem que, no jargão jornalístico, 'fez notícia': o acidente de carro, a cadeira elétrica em que morreu o famoso assassino, o/a protagonista do fato do dia (Marilyn Monroe, Jacqueline Kennedy, Che Guevara). São imagens divulgadas pela imprensa diária: a mesma imagem é vista várias vezes, estampada em pequena ou grande escala, em preto e branco ou em cores, no jornal que se folheia de manhã, tomando café, que o vizinho lê no ônibus, que está pendurado nas bancas de jornal (Ibidem, pág. 647).
}

Temos nos exemplos, acima elencados, uma nítida demonstração das possibilidades de interseção e de interação entre arte e design, que se retroalimentam através das transformações advindas do encontro destas duas áreas do conhecimento que, apesar de distintas se dialogam. Não por acaso, o design vem reconhecido como um espaço onde "arte e técnica" se encontram e, promovem novas linguagens e novas formas de cultura artística e material. Se cada vez mais a arte deixa de ser matéria passando a ser linguagem, o design por outro lado, hoje já podemos assim dizer, trafega entre o "material e o imaterial", aumentando a sua complexidade de entendimento e dificultando a demarcação de seus limites e fronteiras de atuações. Esta realidade, por vez, acarreta por dificultar cada vez mais a sua unicidade terminológica e a sua precisa definição como uma disciplina da área social aplicada.

Interessante notar, que dentro das vertentes da arte contemporânea se fala constantemente em "não-arte", isto é: o que não segue os preceitos plásticos para a realização de uma obra como: forma, equilíbrio, beleza, matéria, cor, textura, etc. e, curiosamente, hoje também já se fala em "não-design" ou pelo menos "não design industrial" como nos provoca Flaviano 
Celaschi em seu livro "Non industrial design: contributi al discorso progettuale". ${ }^{2}$ Nesta mesma linha, encontro em Vilém Flusser (1920-1991) o princípio de "não-coisa" ao assim discorrer:

As não-coisas agora penetram no nosso mundo-ambiente em todas as direções, suplantando as outras. Estas 'não-coisas' se chamam informações [...] As informações sempre existiram e, como nos sugere a própria palavra, tem muito a ver com as 'formas interiores' das coisas. Todas as coisas contêm informações: os livros e os quadros, as embalagens e os cigarros. Ocorre apenas em sabermos lê-las, 'decodifica-las', para trazer à luz as informações. Sempre foi assim, não existe nada de novo nisso [...] mas as informações que hoje invadem o nosso mundo-ambiente e substituem as coisas neles contidos, são de um tipo jamais visto antes: se trata das informações imateriais. As imagens eletrônicas sobre a tela de televisão, os dados armazenados em um computador, todos os filmes e microfilmes, os hologramas e os programas, são de tal forma 'leves' (software) que qualquer tentativa de apanhá-los com as mãos torna-se impossível (FLUSSER, 2003, p. 93).

Mas destaco que foi o teórico e filósofo do design Andrea Branzi (1938) um dos primeiros estudiosos europeus a questionar o termo "design industrial", chegando mesmo a mencionar que a retirada do termo industrial antes adicionado ao termo design seria para ele como uma emancipação, como retirar uma camisa de força da própria atividade e, assim discorre:

O design não é mais aquela atividade voltada à produção em série dos objetos, mas ocupa-se de problemas do habitar, da qualidade e da cultura material, desde o início do design primário e da relação homem/objeto, o mesmo está empenhado em intervir no âmbito da transformação do ambiente artificial [...] Na acepção comum do termo, define-se design industrial como a produção de objetos reproduzíveis industrialmente. Essa definição extremamente linear constitui um erro histórico no debate sobre design; ver esta atividade ligada ao projeto como um processo que transforma os objetos existentes em qualquer coisa que possa ser reproduzida em dez... mil... um milhão de copias, subentende a confusão entre o propósito e o meio do design [...] o design, então, está no centro de um grande problema geral, em que a indústria é um instrumento, um segmento à disposição, mas não é o único parâmetro de referência (BRANZI, Andrea In: SINOPOLI, Nicola. Op. Cit. 1990, p. 181-202). 
Neste sentido, Andrea Branzi propõe o design como um gesto cultural e o insere dentro de um complexo teorema onde se encontram as questões antropológicas e sociais, a questão do consumo, das transformações dos meios produtivos industriais, das multiplicações de diferentes linguagens, das constantes interatividades e hibridizações possíveis e, por isso mesmo Branzi sempre defendeu que as questões inerentes ao projeto, fossem vistas como sendo parte de um processo maior dentro da cultura projetual.

Ao negar o predomínio racional funcionalista na arquitetura e no design, como modelo lógico pensado para essas disciplinas no período Moderno do século XX, Branzi traz à luz o pensamento fuzzy que para ele, é o que mais se assemelha à nossa realidade contemporânea, aonde o constante cenário de caos se estabelece como uma aparente normalidade. Dentro desta lógica, assim expressa Branzi:

\footnotetext{
O termo fuzzy, quase intraduzível, significa literalmente indistinto, intermediário, hibrido, desfocado, esfumaçado e desfocado e, foi usado pela primeira vez nos anos sessenta pelo lógico Lofti Zadec e mais recentemente por Bart Kosko; o mesmo pertence àquela particular tradição da ciência moderna que se moveu para a fronteira inexplorada de superação da rígida lógica dual sobre a qual se baseia a própria ciência [...] Esta evolui como um pensamento indistinto (fuzzy, portanto) que se não mais representa a pureza da geometria e a precisão dos percursos matemáticos, representa, portanto essa realidade esfumaçada (fuzzy, de fato) das galáxias, dos seus estados evolutivos, nebulosos, lácteos, intermediário entre massa e energia. Metáfora figurativa de um novo tempo da nossa ciência, como uma saída positiva da sua crise metodológica e, a caminho de um novo naturalismo (BRANZI, 2006, p. 18-19).
}

Por tudo isso, podemos apontar as significativas e constantes mudanças interpretativas e conceituais ocorridas tanto no âmbito das artes quanto no design a partir do final do século XX e início do Século XXI. Mas, precisamente, podemos igualmente perceber a aproximação dessas duas áreas do conhecimento que buscam respostas às demandas fuzzy em uma sociedade híbrida sempre em transformação, aonde os modelos de referências são sempre as próprias inconstâncias e instabilidades presentes. 


\section{Epistemologia do design contemporâneo}

Vimos que a partir da crise do movimento racional-funcionalista, em prática junto ao modelo Moderno, por durante grande parte do século $\mathrm{XX}$, fez surgir diferentes correntes de pensamentos e teorias que buscassem novos direcionamentos para as disciplinas de cunho projetual, dentre elas o design. Para diversos autores, essas mudanças ocorreram, entre outros, pela decisiva participação do consumidor/usuário, que após os anos sessenta e setenta deixa de ter uma posição passiva para ser agente ativo que influencia a estética, o modo de uso e inclusive o preço dos produtos industriais. Sobre isso, temos em Andrea Branzi esta instigante reflexão:

Em meio a esta profunda transformação, o design viu modificada a sua própria epistemologia de projeto. Essa nasceu com a Bauhaus como uma atividade de pesquisa para objetos definitivos (os velhos produtos standards), capazes de resolver, de uma vez por todas, as necessidades básicas de uma sociedade igualitária. Mas ao contrário, à partir dos anos sessenta e setenta o design foi chamado a projetar objetos não mais destinados àquela inexistente e cinza maioria, mas sim produtos capazes de serem escolhidos pelos próprios consumidores, mirados para nichos de mercados específicos, objetos que utilizavam códigos figurativos variados e minimizados, mas de forte identidade metropolitana. A guiar o design para fora desta vala comum nos anos setenta, foram as vanguardas juvenis, os movimentos radicais e o design experimental, que explodiu em todo o mundo a partir dessa época (BRANZI, 2014, p. 247).

É interessante notar, como ocorrido nas artes (onde o observador passa ser parte intérprete da obra), que desta vez vem ser o consumidor/ usuário a obter um relevante papel na concepção e comercialização dos artefatos industriais. Ao desejar ou repudiar, a seu modo e gosto, o produto durante a sua aquisição, o consumidor passa a ser também um intérprete do design. A real possibilidade de atendimento aos anseios do consumidor, portanto, fizeram emergir novas possibilidades de produção e de consumo e, por consequência novos significados, códigos e linguagens estéticas que foram determinantes para a composição do design nos moldes hoje conhecido.

Por outro lado, a livre circulação de matérias primas, o constante e rápido avanço tecnológico junto à produção fabril, a miniaturização dos componentes, a customização dos produtos (muitas vezes feita pelo próprio cliente) e pôr fim a desmaterialização dos objetos corroboraram também para pôr fim ao termo "design industrial" que, definitivamente, passa a ser "design". Segundo Alessandro Biamonti: 
Isto evidência o quanto seja grave o entendimento gerado pela revolução industrial que o design seja uma disciplina técnica. Portanto é decididamente ultrapassado e fora de lugar o debate sobre o adjetivo 'industrial' que durante quase todo o século XX acompanhou o termo 'design', mas quem se dedicou e dedica à vida profissional nesta atividade, sabe muito bem o quanto o design é um fenômeno cultural, sendo parte mais ampla da cultura material. Uma atividade através da qual o homem, no seu percurso evolutivo e histórico, produziu aqueles signos que hoje nos permitem, por exemplo, de compreender as sociedades antigas através de seus hábitos e costumes, prazeres e fragilidades. Nós, de fato, conhecemos civilizações desaparecidas através do que eles nos deixaram das suas vidas cotidianas. Vasos, joias, ferramentas, armas, tumbas... etc., nos destacam quão profundas são as raízes antropológicas na relação entre o ser humano e o próprio contexto de vida (BIAMONTI, 2015, p. 18-19).

A estoica tentativa "Ulmiana" de conceber um formato de trabalho, através da instituição de equipes próprias de designers dentro das empresas, seguindo por vez uma metodologia lógica e objetiva para a concepção dos produtos industriais, foi substituída pelo design de assinatura, aonde vem valorizado o talento individual e a poética própria de cada profissional, o que de certo modo aproxima hoje os designers do modelo de trabalho praticado pelos artistas. 0 próprio Andrea Branzi ao tecer uma interessante comparação entre o entendimento sobre o design na Itália e na Alemanha, assim discorre:

Podemos dizer que a sua filosofia original não era aquela de um design aplicado à indústria, mas ao contrário à indústria aplicada ao design. A política de Adriano Olivetti não previa que a sociedade devesse se identificar com o modelo da fábrica, mas ao contrário deveria ser a fábrica a intermediar a lógica da sociedade. Em outras palavras, se Dieter Rams pensava na Braun como modelo lógico de um mundo monológico, a Olivetti pensava que deveria ser ela a assemelhar-se com a complexidade da sociedade. Esta contraposição cultural era também evidente no plano logístico e operativo; na Alemanha os designers trabalhavam fisicamente dentro das empresas, integrados nas diversas hierarquias da própria companhia, eram responsáveis pela inteira fase de detalhamento técnico do produto (de todo ciclo produtivo até o parafuso); na Itália os designers trabalhavam nos seus escritórios, com uma relação tipo freelance em respeito ao empreendedor e interagiam criativamente no desenvolvimento dos protótipos para a sua produção... (BRANZI, 2014, p. 131). 
Assistimos, de igual forma, o início do descompasso entre a velha metodologia de projeto, que se propunha como um modelo preciso universal e, o surgimento do metaprojeto como metodologia da complexidade e de respostas díspares como soluções para as condicionantes do projeto. De fato, as repostas do velho marketing com toda a sua segmentação de mercado por classe social, idade, sexo e poder econômico, dá lugar a um modelo transversal de perfil de consumidor que vive em um cenário aonde predomina a constante mudança de comportamento isto é: o usuário e o design deixam de atuar em um cenário estático, movendo-se para um terreno onde a mudança passa ser a única constância.

Outro ponto que não pode ser esquecido, mas ao contrário salientado, trata-se da questão das fronteiras do design que ao se abrirem e se alargarem, constantemente, para outras experiências e contaminações (nem sempre positivas), passam a ser fluidas, amorfas e disformes. ${ }^{4}$ Alberto Bassi ao se referir à fluidez do design em campo expandido assim discorre:

Parece haver em curso, um processo de 'designificação', caracterizado por uma difusa extensão do termo e uma presumida prática onipresente. Melhor ainda, tomando, a propósito, como referência o que seja arte nas palavras do filosofo Mario Perniola, os confins se alargaram tanto ao ponto de o conceito compreender qualquer coisa, vale dizer também nada: de igual forma, hoje parece ser design aquilo que eu decida que seja (BASSI, 2017, p. 49).

O sempre atento Gui Bonsiepe (1934) nos provoca para a necessidade de o design haver contornos próprios ou pelo menos de mais fácil identificação como uma disciplina de cunho projetual. Segundo Bonsiepe, assim procedendo, o design teria mais chances de ser reconhecido como campo de conhecimento próprio e distinto de outras atividades correlacionadas. Ainda observando a complexa delimitação de identidade para o design nos tempos atuais, temos em Ezio Manzini (1945) uma reflexão que nos parece bastante oportuna:

No mundo sólido do passado, existiam 'containers disciplinares seguros', nos quais qualquer um poderia se posicionar sentindo-se bem definido com a sua própria identidade profissional (e, em consequência, no sentido amplo, também na esfera pessoal). Agora não é mais assim: no mundo fluido contemporâneo os containers foram abertos e as suas paredes não são mais protegidas, as definições profissionais e disciplinares se dissolvem e qualquer um deve cotidianamente redefinir a si mesmo e à sua própria bagagem de capacidade e competência [...] é nesse contexto que colocaremos as nossas observações sobre o tema que aqui mais nos interessa: o que realmente é um produto, o que significa projetar e, por fim, o que farão os designers em um mundo fluidificante (MANZINI e JÉGOU In: BERTOLA e MANZINI (org.), 2004, p. 10-17). 


\section{Desafios do ensino de design no século XXI}

A realidade epistemológica, somada às grandes transformações havidas na atividade de design como: o surgimento de novos conceitos de vida tendo como modelo a sustentabilidade socioambiental, a evolução no modo de produzir da indústria que passou de mecânica, para eletrônica e que se torna cada vez mais digital bem como os novos formatos de comercialização via web, fizeram com que os designers se ocupem, cada vez mais, de novos modos de relações, de novas experiências de consumo e de novas propostas de estilos de vida do que da concepção de novos produtos em si, essa que por muito tempo foi a razão e causa primeira do design.

Por outro lado, o forte dinamismo da economia de mercado global aboliu também outras fronteiras antes existentes como a da moral, da política, da economia e do meio ambiente. Desta forma o grande poder do consumo e do descarte, convive hoje lado a lado com a complexidade a que se encontra o design. Tornando cada vez mais difícil a sua pratica, onde à ética deveria prevalecer na concepção de novos produtos inclusive, preceder a estética dos mesmos.

Encontro nas reflexões dos estudiosos Fúlvio Carmagnola e Vani Pasca no manuscrito: "Minimalismo, ética formal e nova simplicidade no design", uma instigante proposta neste sentido:

\footnotetext{
Um movimento comum de redução entre: forma, valores e recursos naturais. Que o design possa interpretar esta inquietante circunstancia cultural como retorno a uma nova simplicidade sem que seja entendida como empobrecimento, mas sim como um neorracionalismo contemporâneo (CARMAGNOLA e PASCA, 2017, p. 67).
}

Interessante perceber, que com a abertura das fronteiras do design para novas experiências, com atividades mais ou menos a ela correlacionadas, hoje já se fala do design da memória, global brand, desmaterialização e serviço, digitalização, virtualização, design no-name, non-design, design como sense making, design para a democracia, low fashion, fast fashion, new craft (o artesanato do novo milênio) que nos permite a personal factory, interaction design, hibridismo e motion design, prosumers (consumidores-produtores) e makers (autoprodutores), e de formas compartilhadas de fundos como o crowdfunding design. Observa-se que grande parte desses modelos de negócios, vem ser no formato digital e virtual dentro da constelação dos e-commerce. Ainda nas palavras de Bassi: 
Presenciamos, de igual forma o nascimento de uma economia hibrida onde em parte temos o mercado capitalista e em parte o mercado colaborativo, onde o mercado capitalista não desaparecerá, mas que não será mais a única força capaz de ditar a agenda econômica do desenvolvimento civil [...] De fato, Rifkin argumenta que passamos de uma economia de mercado para uma economia de interesse comum e preferencialmente imaterial: os "commons" onde prevalece sempre o uso compartilhado e comunitário em detrimento do consumo individual (BASSI, 2017, p. 96).

Tudo isso faz com que o design alcance outro patamar exploratório, aonde as experiências ainda não foram ao todo esgotadas, mas ao contrário inicia-se um novo campo de experimentação e de reflexão para a prática em design. Hoje se fala também em design generativo e de produção aberta, colaborativa e continuada via web, um design com um fim, mas sem um fim programado, com variações que se expandem a partir da colaboração de diferentes indivíduos e atores sociais. De fato, com o crescente aumento do conhecimento informático, aumentam as possibilidades imateriais para o design que gera sempre novas estruturas e destas outras novas estruturas em um constante motum continuum e participativo ad infinitum. Sobre a tendência imaterial do design e suas possíveis vertentes assim descreve Branzi:

Na civilização mercadológica não existe nenhuma diferença entre aquilo que existe, o que não existe e aquilo que poderá existir. 0 sonho faz parte da realidade física e metafísica, o mundo da mídia é um mundo construído, onde a realidade e o reality são equivalentes. A existência humana sempre se alimentou das grandes narrações metafísicas, midiáticas, dos eventos históricos, dos mitos como das experiências físicas. A arquitetura construída perdeu o seu carisma e tem grande dificuldade de se inserir neste complexo sistema onde a 'não-arquitetura' cumpre um papel equivalente. Os projetos dos 'arquistars' nascem justamente desta perda de um papel definido, que vem ser substituído por uma hiper-figuração dentro de uma sociedade abstrata e indiferente aos monumentos físicos, pois a mesma está imersa no líquido amniótico da mercadologia, esse máximo mediador entre produto físico e produto onírico (BRANZI, 2014, p. 188).

Remete-se hoje, portanto, ao conceito de open design, open source e de open innovation, bem como o de open production que permite a contribuição coletiva de diferentes atores sociais como frequentemente ocorre nos FAB Labs e nos laboratórios produtivos abertos, o que reforça e legitima, pelo menos a princípio, a pertinência dos termos design difuso, design aberto e design expandido. 


\section{Conclusão}

Como atento observador, há tempos venho acompanhando as dificuldades das escolas de design em suas exaustivas tentativas de se manterem como principal espaço de formação para os designers. $O$ percurso formativo em design, dentro de um modelo, utilizando as palavras de Zygmunt Bauman (1925-2017), de modernidade fluida onde predomina um cenário de campo aberto, fuzzy e difuso, exige de nossas escolas um ensino, de igual modo, fluido, aberto e difuso.

Hoje podemos atestar que as respostas para as perguntas dos aspirantes a designers, podem não se encontrar ao todo nas escolas mas, dentre outros, nas galerias e museus de artes contemporâneas, nos documentários espontâneos filmados pelos nossos celulares, na música experimental baixadas via Apps, nas mostras e performances temporárias, nas arquiteturas efêmeras, nas provocações hibridas da moda, em novos experimentos estéticos provenientes de longínquos países periféricos, no cinema e na dança e ainda nos espetáculos teatrais alternativos.

No que tange a educação formal em prática nas nossas escolas, é bastante improvável que exista um método ou modelo de percurso formativo que seja universal e aplicável vis a vis à abrangência existente no território expandido do design. Território este aonde as opções operacionais são vastas e sempre em mutação, dependendo ainda de cada contexto e interação pertinente. Em meu entendimento, vem ser o metaprojeto o modelo projetual que mais se aproxima desta complexa realidade, isso ocorre justamente pelo fato do metaprojeto não nos propiciar uma resposta pronta, mas muitas vezes apresentar como resultado final novas perguntas para a questão posta.

Após essas prévias considerações, passamos então a refletir sobre alguns pontos que me parecem bastantes pertinentes: qual modelo de ensino poderia nos indicar um norte para os projetos de design na atualidade? Como equilibrar uma estética racional e uma estética com ênfase na emotividade e na teoria da sensibilidade? Se devemos também projetar o significado e a significância das mercadorias, isto é: procurar dotá-las de sentido em um ecossistema pleno de contínuos excessos pergunta-se: qual estrada nos levaria a tanto? Em se tratando de mercado global, aberto e ilimitado, passamos a outras importantes reflexões também a serem postas: quais signos e significados vêm hoje considerados para produtos destinados ao mercado global? Seria o modelo de design híbrido, com identidade também híbrida, a ser considerado para a concepção de produtos globais? Quais referências culturais locais poderão ser utilizadas na confecção de artefatos, objetos e mercadorias destinadas ao consumo global? Estariam, por fim, as nossas escolas preparadas para formarem novos profissionais considerando todos estes desafios para o design no recém século XXI?

Vale aqui ressaltar que apesar da ampla abertura de fronteiras, com toda fluidez e hibridização ocorridas, deve ser reconhecido que o design continua sendo "design" e arte continua a ser "arte", isto é: dois campos de conhecimentos próprios que se interagem e dialogam entre si. 
Por derradeiro, ressalta-se e deve ser sempre recordado que por termos o homem no centro e referência do design as condicionantes, critérios, vínculos e limites que marcaram o início da atividade de design no passado, ainda se apresentam como referencias legitimas e desafios pertinentes dentro do conceito de design aberto, expandido, fuzzy e difuso.

1 A teoria da affordance "implica que os valores e os significados" das coisas e dos ambientes podem ser percebidos diretamente, acrescentando que tais valores e significados são externos ao perceptor [...] as informações contidas no ambiente se transformam em expressões: signos, dos quais sentido e significado tornam-se uma ação que conduz a um efeito. (ZINGALE, Salvatore. Le inferenze nel design. In DENI, Michela, PRONI, Giampaolo (org.). La semiotica e II progetto: design, comunicazione, marketing. Milano, Ed. Franco Angeli, 2008, p. 63).

2 CELASCHI, Flaviano. Non industrial design: contributi al discorso progettuale. Boca/Novara, Luca Sossella Editore, 2016.

3 Hochschule Fur Gestaltung - HFG conhecida como Escola de UIm (1946-1968)

4 "Não sei se a afirmação 'agora somos todos designers' de Chris Anderson no seu programático Makers, seja na verdade o presente avançado na realidade ou simplesmente um fantástico paradoxo (posto que os paradoxos são sempre uma forma elíptica de realidade), mas uma certeza nós podemos ter: o design não é, e não mais será como antes". BOLELLI, Franco, In BIAMONTI, Alessandro. Design \& Interni: riflessioni su una disciplina in evoluzione tra formazione e professione. Milano, Ed. Franco Angeli, 2015, pag. 09. 


\section{Referências}

ARGAN, Giulio Carlo. Arte Moderna: do iluminismo aos movimentos contemporâneos - crise da arte como ciência europeia. São Paulo: Ed. Companhia das Letras, 1995. BASSI, Alberto. Design Contemporaneo: istruzioni per l'uso. Bologna: Ed. il Mulino, 2017. BIAMONTI, Alessandro. Design \& Interni: riflessioni su una disciplina in evoluzione tra formazione e professione. Milano: Ed. Franco Angeli, 2015.

BONSIEPE, Gui. Design do material ao digital. São Paulo: Ed. Blucher, 2015.

BRANZI, Andrea. Design Industrial: Quale Scuola? L'oggetto della metropoli. In SINOPOLI, Nicola. Op. Cit. p. 181-202. Milano: Ed. Franco Angeli, 1990.

BRANZI, Andrea. Modernità debole e diffusa: Il mondo del progetto all'inizio del XXI secolo. Milano: Skira Editore, 2006.

BRANZI, Andrea. Una generazione esagerata: dai radicali italiani ala crise dela globalizzazione. Milano: Baldini \& Castoldi Editori, 2014.

CELASCHI, Flaviano. Non industrial design: contributi al discorso progettuale. Boca/ Novara: Luca Sossella Editore, 2016.

CUTOLO, Giovanni. Luxo e Design: ética, estética e mercado do gosto. São Paulo: Ed. Perspectiva, 2014.

CUTOLO, Giovanni. o hedonista virtuoso. São Paulo: Ed. Perspectiva, 2012.

ECO, Umberto. Obra Aberta. Tradução Giovanni Cutolo. São Paulo: Ed. Perspectiva, 1968. FATHING, Stephen. Tudo sobre Arte: os movimentos e as obras mais importantes de todos os tempos. Rio de Janeiro: Ed. Sextante, 2011.

FLUSSER, Vilém. Filosofia del Design. Milano: Bruno Mondadori, 2003.

MANZINI, Ezio; JÉGOU, François. Design degli Scenari. In BERTOLA, Paola; MANZINI, Ezio (org.) Design multiverso: appunti di fenomenologia del design. Milano: POLIdesign Edizioni, 2004.

MARCOLLI, Attilio. Teoria Del Campo. Milano: Sanssoni Ed. 1971.

POLANO, Sergio: Achille Castiglioni: tutte le opere, 1938-2000. Milano: Electa, 2001.

ZINGALE, Salvatore. Le inferenze nel design. In DENI, Michela; PRONI, Giampaolo (org.). La semiotica e Il progetto: design, comunicazione, marketing. Milano, Ed. Franco Angeli, 2008. 